\title{
Um olhar amplo sobre a saúde mental pública
}

\author{
A broad look at public mental health \\ Una mirada amplia a la salud mental pública
}

OXFORD TEXTBOOK OF PUBLIC MENTAL HEALTH. Bhugra D, Bhui K, Wong SYS, Gilman SE, editors. New York: Oxford University Press; 2018. 610 p. ISBN: 978-0-19-879299-4.

doi: 10.1590/0102-311X00354920

As políticas de saúde mental no Brasil passam por um momento importante, marcado pela necessidade de consolidação dos avanços alcançados em termos de serviços comunitários e do estabelecimento da Rede de Atenção Psicossocial (RAPS), que integra a assistência de saúde mental a toda a rede de saúde e a demais recursos disponíveis em cada território. Entretanto e ao mesmo tempo, essas políticas têm enfrentado perdas e retrocessos nos últimos anos, que podem ameaçar a consolidação de tais avanços e impedir a superação das fragilidades ainda existentes 1,2,3.

Nesse contexto, torna-se essencial abordar a saúde mental como um campo amplo e integrado à saúde pública, do qual ela mesma depende, de forma interconectada. Tal visão é oferecida pelo Oxford Textbook of Public Mental Health, um verdadeiro compêndio que reúne a experiência de renomados pesquisadores internacionais da área da saúde pública e da saúde mental em um rico trabalho de ampliação da relação entre estes dois temas, propondo uma discussão sobre novas perspectivas para que se concebam e desenvolvam projetos e ações nestes campos de atuação.
Dividida em quatro seções, distribuídas em mais de 600 páginas, a obra contempla temas amplos, como: os princípios da saúde pública, sua aplicação no campo da saúde mental, a interseção desse campo com diversas áreas, a saúde mental de grupos especiais e minoritários, além de uma ampla possibilidade de intervenções. Ao longo de todas as temáticas, há uma grande ênfase no papel da prevenção em saúde mental e da promoção do bem-estar, no nível tanto da sociedade quanto dos indivíduos.

Já de início, o livro reforça a importância de se rever o dualismo que ainda vigora nas ciências e que se reflete em uma forma de se conceber saúde, separando a experiência do corpo da experiência da mente. Consequentemente, as práticas de cuidado acabam se concentrando no corpo e deixando a mente de fora das discussões e esforços políticos em prol da saúde e saúde mental. Do mesmo modo, é destacada outra problemática que ocorre no processo de concepção de cuidado e de criação de políticas, que, ao priorizar ações em torno da doença mental, deixa de investir em ações que tenham como centro medidas preventivas e, sobretudo, a promoção da saúde mental. Ressalta-se, também, nessa mesma linha argumentativa, o papel fundamental dos determinantes sociais, ambientais, culturais, dentre outros, na produção de saúde e no agravamento de doenças, convidando o leitor a ter um olhar atento ao sujeito em seu contexto, sem restringi-lo à sua experiência física e biológica. Desse modo, convida o leitor a estar atento 
ao fato de que os aspectos biomédicos tendem a ser afetados pelos determinantes sociais, culturais e ambientais, o que implica considerar tais determinantes efetivamente, em termos de planejamento de ações de prevenção, promoção e cuidado em saúde mental. Trata-se, portanto, da defesa de uma saúde mental coletiva, em uma perspectiva tanto macro quanto micropolítica.

Dentre as variadas reflexões trazidas ao longo dos capítulos em relação a novas perspectivas em saúde mental pública, cabe destacar o questionamento no que se refere à tendência em se focar no processo de adoecimento e na doença enquanto ameaça populacional, em termos de políticas públicas, ou mesmo no doente, enquanto organismo individual, ao invés de se focar em saúde como possibilidade de promoção coletiva a ser investida. Um olhar que aponte para novas práticas nessa direção deve ter em vista a abordagem das capacidades em saúde de dada comunidade e de seus indivíduos, e não nas incapacidades e limitações individuais de forma restrita. Nessa direção, em que se prioriza o coletivo, no que concerne ao processo de adoecimento/cuidado e, principalmente, à produção de saúde, entrelaçamentos entre políticas públicas e saúde mental vão sendo apresentados sob uma ótica de equidade, justiça social e direitos humanos, o que nos agrega importantes reflexões e inspirações a serem posteriormente contextualizadas em nosso território nacional, como avanço e em consonância com as diretrizes do Sistema Único de Saúde (SUS) e da Reforma Psiquiátrica. Para tanto, uma "abordagem das capacidades" (capabilities approach) poderia reatualizar as formas de cuidado, por meio da proposta de nutrir, proteger, prover e expandir as capacidades individuais de sujeitos em condições desfavoráveis de saúde no âmbito mental, em um esforço de habilitá-los a perseguir, conceber e revisar seus planos de vi- da, mantendo o foco na busca por integridade e por dignidade humana. Além disso, é ressaltada a consideração da inserção dos sujeitos em um sistema econômico de desigualdades sociais e desigualdades em saúde mental, fazendo uso de instrumentos para sustentabilidade em saúde mental, educação em saúde, assim como para o desenvolvimento de pesquisa em saúde pública.

Ao longo dos capítulos, temas específicos vão sendo desenvolvidos aproximando práticas, produção de saberes e planejamento de políticas públicas no intuito de construir e fortalecer princípios em saúde mental pública. Nesse sentido, o tema da saúde mental em uma perspectiva pública vai sendo aprofundado a partir da sua articulação com demais temas, tais como: saúde ocupacional e do trabalhador, contexto escolar e relações interpessoais, questões de gênero, interseccionalidade (gênero, raça e classe social), diferenças de acesso, desigualdades históricas e sociais, dificuldades intelectuais, doenças congênitas e sexualmente transmissíveis, abuso de álcool e drogas, estilo de vida, mídia social e telessaúde na saúde mental, dentre outros.

Portanto, trata-se de uma obra relevante para o contexto contemporâneo e nacional, ao expandir a visão sobre a assistência em saúde mental, por meio de uma saúde mental global e da sua sedimentação no campo da saúde pública, o que demanda o uso de evidências científicas e de uma abordagem mais integrativa 4,5 .

Daiana Paula Milani Baroni 1

Mário César Rezende Andrade 1

1 Universidade Federal de São João del-Rei, São João del-Rei,

Brasil.

daianapaulam@yahoo.com.br 


\section{Colaboradores}

Os autores participaram conjuntamente da redação da resenha.

\section{Informações adicionais}

ORCID: Daiana Paula Milani Baroni (0000-00015210-0650); Mário César Rezende Andrade (00000003-2784-5209).
1. Almeida JMC. Política de saúde mental no Brasil: o que está em jogo nas mudanças em curso. Cad Saúde Pública 2019; 35:e00129519.

2. Cavalcanti MT. Perspectivas para a política de saúde mental no Brasil. Cad Saúde Pública 2019; 35:e00184619.

3. Onocko-Campos RT. Saúde mental no Brasil: avanços, retrocessos e desafios. Cad Saúde Pública 2019; 35:e00156119.

4. Collins P, Patel V, Joestl S, March D, Insel TR, Daar AS. Grand challenges in global mental health. Nature 2011; 475:27-30.

5. Wahlbeck K. Public mental health: the time is ripe for translation of evidence into practice. World Psychiatry 2015; 14:36-42. 